\title{
Sequences of psychrophilic fungi amplified from glacier-preserved ascolichens
}

\author{
Paula T. DePriest, Natalia V. Ivanova, Dianne Fahselt, Vagn Alstrup, \\ and Andrea Gargas
}

\begin{abstract}
Ribosomal DNA sequences were amplified from subfossils of the ascolichen Umbilicaria cylindrica (L.) Delise ex Duby collected at the ablating edges of Greenland glaciers. Surprisingly, phylogenetic analysis indicated that the amplified rDNA sequences were not closely related to those of the lichen-forming fungus but rather represented two groups of psychrophilic basidiomycetes (orders Cystofilobasidiales and Sporidiales) and one group of ascomycetes (order Leotiales). Two of these groups, the Sporidiales and the Leotiales, include other fungi previously detected in DNA extracted from the grass clothing of the Tyrolean Iceman desiccated and frozen for over 3000 years and also in 2000- and 4000-year-old ice core samples from northern Greenland. Large subunit ribosomal DNA sequences representing the group Cystofilobasidiales were nearly identical to those of the basidioyeast saprobe Mrakia frigida. The adjacent internal transcribed spacer sequence was more than $98 \%$ similar to those from three samples of $U$. cylindrica from different sites that had been subjected to ice burial for various lengths of time, suggesting they also were Mrakia sequences. Although ancient contamination of multiple $U$. cylindrica specimens with fungi such as Mrakia cannot be ruled out, it is more probable that saprobic colonization of the subfossil tissues by psychrophilic fungi proceeded during recent ice melt.
\end{abstract}

Key words: ancient DNA, small subunit ribosomal DNA, 18S ribosomal DNA, phylogenetic analysis, psychrophilic fungi, lichen-forming fungi.

\begin{abstract}
Résumé : Les auteurs ont amplifié les séquences de l'ADN ribosomal provenant de subfossiles de l'ascolichen, Umbilicaria cylindrica (L.) Delise ex Duby, récoltés sur les marges d'ablation de glaciers, au Groenland. De façon surprenante, les analyses phylogénétiques indiquent que les séquences de rADN amplifiées ne sont pas étroitement apparentées avec celles du champignon formant ce lichen, mais représente plutôt deux groupes de champignons basidiomycètes psychrophiles (ordre des Cystofilobasidiales et des Sporidiales) et un groupe d'ascomycètes (ordre des Léotiales). Deux de ces groupes, les Sporidiales et les Léotiales, incluent d'autres champignons préalablement décelés dans l'ADN extrait des habits constitués d'herbes portés par l'homme des glaces Tyroléen desséché et congelé depuis plus de 3000 ans, ainsi que de carottes de glaces âgée de 2000 et 4000 ans, échantillonnées au nord du Groenland. Les grandes sous-unités des séquences d'ADN représentant le groupe des Cystofilobasidiales sont presqu'identiques à celles de la basidiolevure saprophyte, le Mrakia frigida. La séquence de l'espaceur interne transcrit adjacent ressemble à plus de $98 \%$ à celles provenant de trois échantillons de l'U. cylindrica récoltés sur différents sites ayant été soumis au recouvrement par la glace pendant différentes périodes de temps, ce qui suggère qu'il s'agirait également de séquences du Mrakia. Bien qu'on ne puisse exclure la possibilité de contamination des spécimens multiples de l'U. cylindrica par des champignons tels que le Mrakia, il est fort probable que la colonisation saprophyte des tissus subfossiles par des champignons psychrophiles se soit effectuée au cours d'un récent dégel des glaces.
\end{abstract}

Mots clés : ADN ancien, petite sous unité de l'ADN ribosomal, ADN ribosomal 18S, analyse phylogénétique, champignon psychrophile, champignon formant des lichen.

[Traduit par la Rédaction]

Received April 28, 2000. Published on the NRC Research Press website on December 7, 2000.

P.T. DePriest. ${ }^{1}$ Department of Botany, NHB-166, National Museum of Natural History, Smithsonian Institution, Washington, DC 20560-0166, U.S.A.

N. V. Ivanova. ${ }^{2}$ Department of Botany, NHB-166, National Museum of Natural History, Smithsonian Institution, Washington, DC 20560-00166, U.S.A and Plant Genosystematics Laboratory, Department of Evolutionary Biochemistry, Belozersky Institute of Physico-Chemical Biology, Moscow Lomonosov State University, Moscow, Russia 117234.

D. Fahselt. Department of Plant Sciences, University of Western Ontario, London, ON N6A 5B7, Canada.

V. Alstrup. Botany Department, University of Dar Es Salaam, P.O. Box 35060, Dar Es Salaam, Tanzania.

A. Gargas. Department of Botany, 430 Lincoln Drive, University of Wisconsin, Madison, WI 53706-1381, U.S.A.

${ }^{1}$ Author to whom all correspondence should be addressed (e-mail: depriest@onyx.si.edu).

${ }^{2}$ Present address: Group of Automated DNA Sequencing, Engelhardt Molecular Biology Institute, Vavilova Street, 32, Moscow, Russia, 117984. 


\section{Introduction}

DNA preserved in ancient materials offers an enticing window on biological evolution. However, damage to ancient DNA (Rogan and Salvo 1990) limits the view to short fragments of genomes. Although such fragments may theoretically suffice for molecular analyses, their damaged state makes them inefficient templates for the highly sensitive polymerase chain reaction (PCR) and, therefore, even small quantities of foreign DNA may obscure their amplification. Foreign DNA may infiltrate tissues of glacier-covered materials before or during ice entrapment, or in the brief time when they are exposed by melting. In addition, ancient DNAs may also be contaminated by DNA from modern saprobic organisms, laboratory sources, or even human handling. One major challenge in genetically characterizing ancient materials is discriminating among constituent DNAs.

In contrast to materials fossilized for millions of years (Cano et al. 1993; DeSalle et al. 1992; Golenberg et al. 1990; Woodward et al. 1994), subfossils of lesser age (Cooper 1994; Handt et al. 1994; Nielsen et al. 1994; Higuchi et al. 1984; Pääbo 1985; Pääbo et al. 1989; Ubaldi et al. 1996, Willerslev et al. 1999), such as lichens exposed by presentday ablation of glaciers, may yield DNA sequences of sufficient quality and quantity to permit highly resolved phylogenetic analyses. Subfossil lichens have been observed in a 2- to 5-m broad zone at several sites along the ablating margins of Greenland's ice cap (Alstrup 1995; Fahselt and Alstrup 1997a, 1997b; Fahselt et al. 1995). These lichens were covered by ice for up to 1350 years and exposed by ice melt for less than 1 year (Alstrup 1995). When exposed for more than 1 year, $>5 \mathrm{~m}$ from the margin, the samples completely deteriorated. Subfossil lichen specimens closest to the ice margins, which were morphologically quite well preserved, presumably were exposed by ice melt for only days or weeks. Lichens, notoriously slow to grow, would not have established and reached mature sizes in such a short time. These subfossils should yield high quality DNA for molecular systematics investigations as long as they were not contaminated by other organisms either during glacier coverage or during ice melt and exposure. We examined subfossil specimens of Umbilicaria cylindrica (L.) Delise ex Duby, which was the most abundant subfossil in these sites.

\section{Materials and methods}

\section{Samples and radiocarbon dating}

Subfossil lichens were collected from newly exposed sites within $1 \mathrm{~m}$ of the ice margins approximately $4 \mathrm{~km} \mathrm{~N}$ of Qaanaaq in northwest Greenland $\left(77^{\circ} 31 \mathrm{~N}, 69^{\circ} 16^{\prime} \mathrm{W}\right.$, elevation of $\left.400 \mathrm{~m}\right)$ in 1991 and 1993 (see Alstrup 1995), at Cap Georg Cohn $\left(80^{\circ} 16^{\prime} \mathrm{N}\right.$, $26^{\circ} 14^{\prime} \mathrm{W}$, elevation of $\left.400 \mathrm{~m}\right)$, and at Amdrup Højland $\left(80^{\circ} 20^{\prime} \mathrm{N}\right.$, $25^{\circ} 43^{\prime} \mathrm{W}$ ) in northeast Greenland in 1995 (see Fahselt and Alstrup $1997 a, 1997 b$ ). Twenty-five subfossil lichen samples were collected at the three locations listed in Table 1 as close to the ice-margin as possible. Samples were placed in clean paper packets, air-dried, and held at $20^{\circ} \mathrm{C}$. Eventually subfossils were archived at $-80^{\circ} \mathrm{C}$ in laboratories used for handling ancient material (see Table 1).

The dried subfossil lichens were radiocarbon dated using standard techniques by IsoTrace Laboratories (Toronto, Ont.) or AMS Laboratories (University of Aarhus, Aarhus, Denmark), as designated in Table 1 (see also Fahselt et al. 1995). Small samples
(28 mg for 93-G7) were treated sequentially with hot $\mathrm{HCl}$ and fresh $\mathrm{NaOH}$, combusted and graphitized, and analyzed using accelerator mass spectrometry (AMS) for the amount of ${ }^{14} \mathrm{C}$ in relation to the amounts of ${ }^{13} \mathrm{C}$ and ${ }^{12} \mathrm{C}$. Specimen age was calibrated with the bidecal data set INTCAL93.14C (Stuiver and Reimer 1993). Subfossil tissues that remained after destructive sampling for radiocarbon dating were used for thin-layer chromatography of lichen compounds and extraction of DNA, and representative samples of these are deposited at US.

Modern specimens of 11 umbilicate lichens were collected at the locations listed in Table 2. Vouchers were either deposited at US or kept in the personal collection of N.V. Ivanova (Hb. Ivanova).

\section{Thin-layer chromatography}

Subfossil samples were screened for lichen compounds such as gyrophoric acid and lecanoric acid, by standard methods of thinlayer chromatography (see Culberson and Ammann 1970) after extraction of at least $0.03 \mathrm{~g}$ dry weight of thallus with acetone.

\section{Precautions and controls}

DNA isolation and PCR set-up was completely separated from PCR amplification and sequencing. Pre-PCR laboratories set up for handling ancient DNA were used for DNA isolation and PCR setup (Table 1) and a separate post-PCR laboratory for PCR amplification, PCR product cleaning and direct sequencing. Each laboratory had separate pipettes, chemicals, and reagents. Fungal materials had not been handled in either of the pre-PCR laboratories. Controls for contamination during collection included modern materials that were collected and handled in parallel in a separate laboratory, and controls for contamination during DNA isolation and PCR amplification included 1) extraction from an empty tube, and 2) PCR reaction without DNA template.

\section{Extraction of DNA}

DNA was isolated from approximately $1 \mathrm{~cm}^{2}$ of thallus tissue or $30 \mathrm{mg}$ of desiccated fresh or subfossil samples. A sample containing only extraction reagents, but no subfossil tissue, provided a control for the extraction procedures. Samples handled in 1993 (Table 1) were extracted with acetone to remove phenolic compounds; this step was omitted in 1994 and 1996. Each sample was ground to a fine powder in liquid nitrogen. Three extraction methods were used. (1) In 1993, powdered samples were extracted in $2 \times$ CTAB buffer. The supernatant was deproteinated twice using chloroform - isoamyl alcohol (24:1) and DNA was precipitated by isopropanol in the presence of $300 \mathrm{mM}$ sodium acetate. The DNA pellet was washed with $80 \%$ ethanol and re-suspended in $10 \mathrm{mM}$ Tris-HCI (pH 8), 1 mM EDTA. (2) In 1994, powdered samples were extracted with $4 \mathrm{M}$ guanidinium isothiocyanate, $50 \mathrm{mM}$ Tris$\mathrm{HCl}(\mathrm{pH}$ 7.6), $10 \mathrm{mM}$ EDTA, $0.5 \%$ sarkosyl. The supernatant was deproteinated once using chloroform - isoamyl alcohol (24:1), and the DNA precipitated onto GeneClean Glassmilk (Bio101, Carlsbad, Calif.) in the presence of NaI. The glass-bound DNA was washed three times with NewWash Solution (Bio101), and the DNA was resuspended in $\mathrm{dH}_{2} \mathrm{O}$. Reagents were treated with nucleases. (3) In 1996, powdered samples were extracted in $2 \times$ CTAB buffer as in method 1 (above), and the DNA precipitated onto glassmilk as in method 2 (above).

\section{PCR amplification and cycle sequencing}

For each sample, total genomic DNA (1-10 ng) was used for PCR amplifications of portions of the fungal ribosomal DNA (rDNA) with various fungal-specific primers (Gargas and DePriest 1996) in $10 \mathrm{mM}$ Tris (pH 8.3), $50 \mathrm{mM} \mathrm{KCI}$, and $2 \mathrm{mM} \mathrm{MgCl}_{2}$, with $200 \mu \mathrm{M}$ of each primer and 1.25 units of KlenTaq (Ab Peptides, St. Louis, Mo.). PCR was performed for 30 cycles: $95^{\circ} \mathrm{C}$ for $1 \mathrm{~min}$ for DNA denaturation; $50^{\circ} \mathrm{C}$ for $1 \mathrm{~min}$ for primer annealing; 
Table 1. Collection and processing of subfossil materials from northern Greenland arranged by collecting location.

\begin{tabular}{|c|c|c|c|}
\hline Collection and extraction & Qaanaaq & Cap Georg Cohn & Amdrup Højland \\
\hline Date $(\mathrm{s})$ collected & 1991,1993 & 1995 & 1995 \\
\hline Collection numbers & 93-G1-G10, 94-G11-G19, 96-G5-G6 & 96-G1-G2 & 96-G3-G4 \\
\hline Radiocarbon dating & $1350 \pm 60$ years $^{a}$ & $325 \pm 80$ years $^{b}$ & 40 years $^{b, c}$ \\
\hline $\begin{array}{l}\text { Laboratory used for DNA } \\
\text { isolation and PCR set-up }\end{array}$ & $\begin{array}{l}\text { Botany (1993), CAL (1994), } \\
\text { and LMS (1996) }\end{array}$ & LMS (1996) & LMS (1996) \\
\hline Methods used ${ }^{e}$ & $1,2,3$ & 3 & 3 \\
\hline
\end{tabular}

${ }^{a}$ 93-G7 radiocarbon dated at $1550 \pm 60$ years, IsoTrace Laboratories, Toronto, one sample only.

${ }^{b}$ AMS Laboratories, University of Aarhus, Aarhus, Denmark.

${ }^{c}$ IsoTrace Laboratories, Toronto.

${ }^{d}$ All laboratories are located within the Smithsonian Institution's Museum Support Center, Suitland, Md. Botany, DNA laboratory of the Department of Botany; CAL, molecular facility of the Conservation Analytic Laboratory; LMS, DNA isolation facility of the Laboratory of Molecular Systematics.

${ }^{e}$ Method 1, CTAB buffer extraction with isopropyl precipitation; method 2, guanidium isothiocyanate buffer extraction with glassmilk precipitation; method 3, CTAB buffer extraction with glassmilk precipitation.

Table 2. Collection data and GenBank accession numbers for modern material of umbilicate lichens.

\begin{tabular}{llc}
\hline Extant taxon & Collection data & GenBank accession No. \\
\hline Lasallia papulosa & U.S.A, North Carolina, Mount Mitchell, 1994 DePriest V21 (US) & AF294918 \\
Lasallia pertusa & Russia, Altai Republic, 1993 Lunke et al., Umbilicariaceae Exs. 22 (US) & AF294919 \\
Lasallia pustulata & Ukraine, Ivano-Frankovskaya region, 1993 Borissenko \& Ivanova L5 (Hb. Ivanova) & AF294920 \\
Lasallia rossica & Russia. Siberia, 1993 Zhurbenko, Umbilicariaceae Exs. 24 (US) & AF088238 \\
Umbilicaria cylindrica & Greenland, Qaanaaq Glacier, 1993 Alstrup C4 (US) & AF294921 \\
Umbilicaria cylindrica & Ukraine, Ivano-Frankovskaya region, 1993 Borissenko \& Ivanova 35 (Hb. Ivanova) & AF294922 \\
Umbilicaria deusta & Ukraine, Ivano-Frankovskaya region, 1993 Borissenko \& Ivanova D1 (Hb. Ivanova) & AF294923 \\
Umbilicaria deusta & Ukraine, Ivano-Frankovskaya region, 1993 Borissenko \& Ivanova L7 (Hb. Ivanova) & AF294924 \\
Umbilicaria polyphylla & Ukraine, Ivano-Frankovskaya region, 1993 Ivanova D3 (Hb. Ivanova) & AF294925 \\
Umbilicaria subglabra & Turkey. Prov. Travzon, 1990 John, Umbilicariaceae Exs. 17 (US) & AF088253 \\
Umbilicaria vellea & Ukraine, Ivano-Frankovskaya region, 1993 Ivanova 26 (Hb. Ivanova) & AF294926 \\
\hline
\end{tabular}

$72^{\circ} \mathrm{C}$ for 2 min for primer extension. All amplifications included negative controls with $\mathrm{dH}_{2} \mathrm{O}$ replacing genomic DNA, including the extraction control. Nearly complete nuclear small subunit (SSU) rDNAs were amplified from subfossils $94-$ G11 and 94-G12 and modern lichens Lasallia rossica (GenBank accession No. AF088238) and Umbilicaria subglabra (GenBank accession No. AF088253) using oligonucleotide primers that preferentially amplify fungal sequences, as previously described (Gargas et al. 1995; Gargas and DePriest 1996; Stenroos and DePriest 1998). The SSU rDNAs from these samples were amplified as two overlapping fragments, one fragment from the $5^{\prime}$ half including nucleotides 54-872 and one from the $3^{\prime}$ half including nucleotides 8021750 (numbered relative to Saccharomyces cerevisiae SSU rDNA). The SSU rDNA region between nucleotides 802 and 1313 (numbered relative to Saccharomyces cerevisiae SSU rDNA) was amplified from an additional nine subfossil specimens (93-G1 - G10) and from nine modern umbilicate lichens (see Table 3). DNA isolated from subfossils 94-G11, 96-G1, 96-G3, and 96-G5 was used for PCR amplification of the rDNA internal transcribed spacer (ITS) and 5.8S subunit, as described in Ivanova et al. (1999), between primer nu-SSU-1566-5' in the SSU rDNA (Gargas and DePriest 1996) and primer ITS4 in the LSU (White et al. 1990). In addition, a region of the nuclear large subunit (LSU) rDNAs between nucleotides 1 and 638 (numbered relative to $S$. cerevisiae LSU rDNA) was amplified from two subfossils 96-G1 and 96-G3 using the primers ITS5 in the SSU rDNA (White et al. 1990) and LR3 (Vilgalys and Hester 1990).

Double-stranded PCR products (50 ng) were sequenced using PRISM Ready Reaction DyeDeoxy Terminator Cycle Sequencing
Kit (PE Biosystems, Foster City, Calif.) with detection on a 373A automatic sequencing apparatus (PE Biosystems) as in Gargas et al. (1995). Sequence fragments were assembled into full-length sequences using Sequence Navigator 1.0 (Applied Biosystems); both strands were sequenced from multiple primers. The overlapping fragments from Lasallia rossica and U. subglabra were compiled as a nearly complete SSU rDNA sequence; similar fragments from the subfossils $94-$ G11 and $94-$ G12 were treated as separate sequences. Twenty-eight partial or complete rDNA sequences were deposited in GenBank, 13 nuclear SSU rDNA sequences from 11 subfossil samples (GenBank accession Nos. AF294927-AF294939) and nine nuclear SSU rDNA sequences from nine modern umbilicate lichens (GenBank accession Nos. AF294918-AF294926), four nuclear rDNA ITS sequences from four subfossil samples (GenBank accession Nos. AF294940-AF294943), and two nuclear LSU rDNA sequences from two subfossil samples (GenBank accession Nos. AF294944-AF294945).

\section{Sequence alignment and phylogenetic analysis}

Thirteen nuclear SSU rDNA sequences from 11 subfossil samples and 11 from nine modern umbilicate lichens were aligned with those from 43 ascomycetous, 43 basidiomycetous, and 3 zygomycetous representatives, as described in Gargas et al. (1995), with additional representatives of the orders Cystofilobasidiales and Sporidiales, and two partial nuclear SSU rDNA sequences, T44NS-7 (GenBank accession No. X88773) and T44NS-4 (GenBank accession No. X88772) associated with the grass clothing of the Tyrolean Iceman (Rollo et al. 1995). The aligned sequences of 1993 nucleotide positions (including gaps) were ana- 
Table 3. Regions of the small subunit (SSU), internal transcribed spacer, 5.8S subunit (ITS-5.8S), and large subunit (LSU) nuclear ribosomal DNA (rDNA) sequenced from subfossil and extant ascolichen specimens.

\begin{tabular}{|c|c|c|c|}
\hline \multirow[b]{2}{*}{ rDNA region } & \multirow[b]{2}{*}{ Nucleotides (nt) } & \multicolumn{2}{|l|}{ Specimens } \\
\hline & & Subfossil & Extant \\
\hline \multirow[t]{15}{*}{ SSU } & \multirow[t]{2}{*}{ SSU nt $72-872$} & 94-G11A (AF294927) ${ }^{a}$ & Lasallia rossica $(\mathrm{AF} 088238)^{b}$ \\
\hline & & 94-G12A (AF294928) ${ }^{a}$ & Umbilicaria subglabra (AF088253) \\
\hline & \multirow[t]{2}{*}{ SSU nt $819-1750$} & 94-G11B (AF294929) ${ }^{a}$ & Lasallia rossica $(\mathrm{AF} 088238)^{b}$ \\
\hline & & 94-G12B (AF294930) ${ }^{a}$ & U. subglabra $(\mathrm{AF} 088253)^{b}$ \\
\hline & \multirow[t]{11}{*}{ SSU nt $819-1293$} & 93-G6 (AF294931) ${ }^{a}$ & Lasallia papulosa $(\mathrm{AF} 294918)^{a}$ \\
\hline & & 93-G7 (AF294932) ${ }^{a}$ & Lasallia pertusa (AF294919) ${ }^{a}$ \\
\hline & & 93-G9 (AF294933) ${ }^{a}$ & Lasallia pustulata $(\mathrm{AF} 294920)^{a}$ \\
\hline & & 94-G13 (AF294934) ${ }^{a}$ & Lasallia rossica $(\mathrm{AF} 088238)^{b}$ \\
\hline & & 94-14 (AF294935) ${ }^{a}$ & U. cylindrica $(\mathrm{AF} 294921)^{a}$ \\
\hline & & 94-15 (AF294936) ${ }^{a}$ & U. cylindrica $(\mathrm{AF} 294922)^{a}$ \\
\hline & & 94-16 (AF294937) ${ }^{a}$ & U. deusta $(\mathrm{AF} 294923)^{a}$ \\
\hline & & 94-17 (AF294938) ${ }^{a}$ & U. deusta $(\mathrm{AF} 294924)^{a}$ \\
\hline & & 94-18 (AF294939) ${ }^{a}$ & U. polyphylla $(\mathrm{AF} 294925)^{a}$ \\
\hline & & & U. subglabra $(\mathrm{AF} 088253)^{b}$ \\
\hline & & & U. vellea $(\mathrm{AF} 294926)^{a}$ \\
\hline \multirow[t]{21}{*}{ ITS-5.8S } & \multirow[t]{21}{*}{ SSU nt 1566- LSU nt 40} & 94-G11 (AF294940) ${ }^{a}$ & Lasallia pennsylvanica $(\mathrm{AF} 096202)^{c}$ \\
\hline & & 96-G1 (AF294941) ${ }^{a}$ & Lasallia pertusa $(\mathrm{AF} 096203)^{c}$ \\
\hline & & 96-G3 (AF294942) ${ }^{a}$ & Lasallia rossica $(\mathrm{AF} 096201)^{c}$ \\
\hline & & 96-G5 (AF294943) ${ }^{a}$ & U. americana $(\mathrm{AF} 096218)^{c}$ \\
\hline & & & U. antarctica $(\mathrm{AF} 096213)^{c}$ \\
\hline & & & U. crustulosa $(\mathrm{AF} 096215)^{c}$ \\
\hline & & & U. cylindrica $(\mathrm{AF} 096199)^{c}$ \\
\hline & & & U. cylindrica $(\mathrm{AF} 096209)^{c}$ \\
\hline & & & U. decussata (AF096214) ${ }^{c}$ \\
\hline & & & U. deusta $(\mathrm{AF} 096206)^{c}$ \\
\hline & & & U. hyperborea $(\mathrm{AF} 096216)^{c}$ \\
\hline & & & U. leiocarpa $(\mathrm{AF} 096211)^{c}$ \\
\hline & & & U. lyngei $(\mathrm{AF} 096217)^{c}$ \\
\hline & & & U. muehlenbergii (AF096204) ${ }^{c}$ \\
\hline & & & U. nylanderiana $(\mathrm{AF} 096205)^{c}$ \\
\hline & & & U. rigida $(\mathrm{AF} 096212)^{c}$ \\
\hline & & & U. ruebeliana $(\mathrm{AF} 096219)^{c}$ \\
\hline & & & U. spodochroa $(\mathrm{AF} 096207)^{c}$ \\
\hline & & & U. subglabra $(\mathrm{AF} 096200)^{c}$ \\
\hline & & & U. umbilicarioides $(\mathrm{AF} 096210)^{c}$ \\
\hline & & & U. vellea $(\mathrm{AF} 096208)^{c}$ \\
\hline \multirow[t]{2}{*}{ LSU } & \multirow[t]{2}{*}{ LSU nt $1-653$} & 96-G1 (AF29492344) ${ }^{a}$ & \\
\hline & & 96-G3 (AF29492345) ${ }^{a}$ & \\
\hline
\end{tabular}

Note: GenBank accession numbers are given in parentheses.

${ }^{a}$ Sequences reported in the present study.

${ }^{b}$ Sequences reported in Stenroos and DePriest (1998).

${ }^{c}$ Sequences reported in Ivanova et al. (1999).

lyzed by maximum parsimony in PAUP 4 (Swofford 1999) using a heuristic search repeated 100 times with random addition of sequences. All characters were included and equally weighted, invariant characters were ignored, alignment gaps were treated as missing data, and branch lengths equal to 0 were collapsed to polytomies. The analysis produced unrooted networks that were rooted using three zygomycetous fungi as outgroup taxa. Bootstrap and Jackknife percentages to assess support for each branch were determined for 200 resamplings of the data set; values of $>75 \%$ provided strong support for the monophyly of groups such as Ascomycetes and Basidiomycetes (see Gargas et al. 1995). The most parsimonious trees were used as starting trees for a maximum likelihood analysis (PAUP 4.0) using the Rogers-Swofford approximation method. The analysis used the Hasegawa-KishinoYano (1985) model assuming two substitution types and equal rates of evolution among sites, and estimating transition/transversion ratios via maximum likelihood, but without enforcement of a molecular clock. The trees generated in the maximum parsimony and maximum likelihood analyses above were compared using the Kishino-Hasegawa test of their likelihood values, expressed as -ln likelihood. under a simple model of two substitution types and estimated transition/transversion (ti/tv) ratios as above.

\section{Results and discussion}

The discovery of ascolichens within $1 \mathrm{~m}$ of a melting ice front suggested their emergence from glacial entrapment within days or weeks. Radiocarbon dating of vegetation samples from one site (Qaanaaq) indicated preservation beneath ice 
Fig. 1. Sequence alignment for a conserved $100 \mathrm{nt}$ region of SSU rDNA (relative to Saccharomyces cerevisiae 972-1071) from 11 subfossil-associated sequences (Genbank accession Nos. AF294929-AF294939), nine extant umbilicate lichens (Genbank accession Nos. AF294918-AF294926), reference sequences from the ascomycetes S. cerevisiae (Genbank accession Nos. J01353 and M27607) and Neurospora crassa (Genbank accession No. X04971), and potential DNA contaminants, the lichen alga Trebouxia impressa (Genbank accession No. Z21551) and Homo sapiens (Genbank accession No. U13369). Nucleotides in common with the reference sequence S. cerevisiae are indicated by dots (.). Ambiguous nucleotides are indicated by R (A or G) and M (A or C), and gaps required for sequence alignment by dashes (-). Pairs of nucleotide positions with the same numbers $(1,2$ or 3$)$ represent compensatory changes that retain pairing of helices in putative secondary structures. Note that subfossil sequence $93-\mathrm{G} 7$ (Genbank accession No. AF294932) has many nucleotide differences from other subfossil associated sequences.

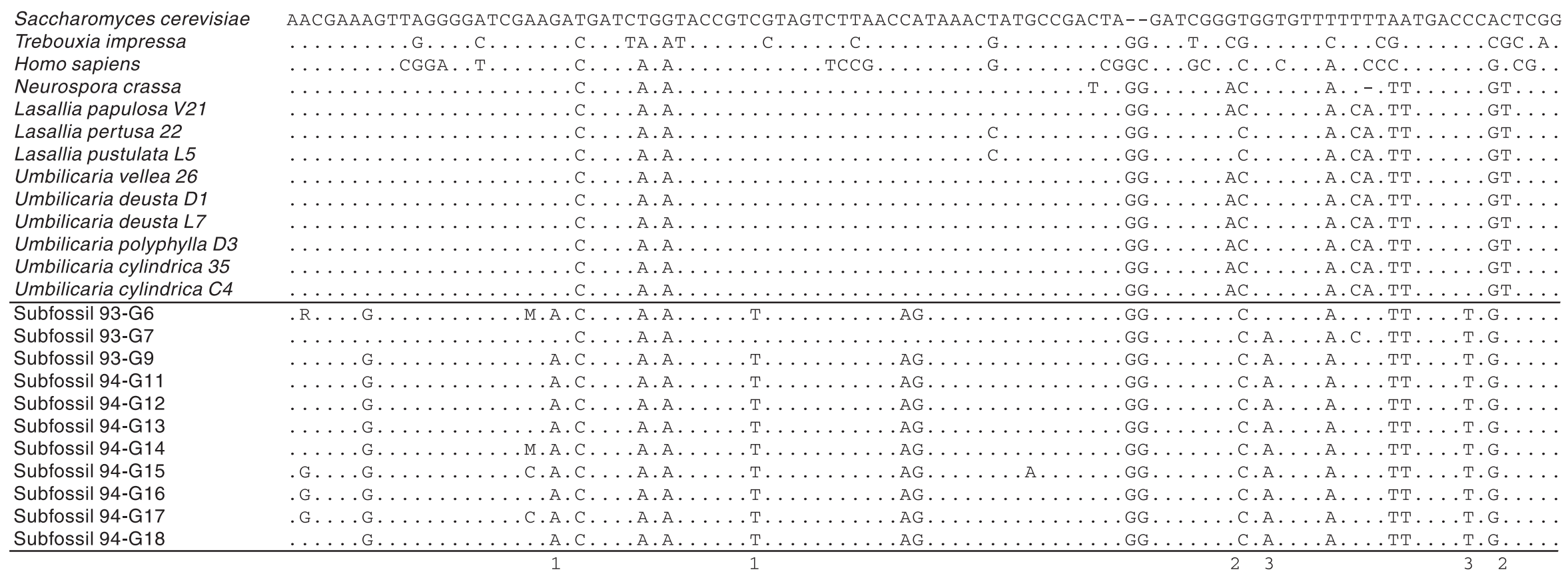


Fig. 2. Sequence alignment for a 555-nt region of the nuclear rDNA including ITS1, ITS2, and 5.8S subunit from four subfossilassociated sequences (Genbank accession Nos. AF294940-AF294943). Nucleotides in common with the reference sequence subfossil 96-G1 are indicated by dots (.), nucleotide differences by the nucleotide, and gaps required for sequence alignment by dashes (-). The positions of ITS1, 5.8S, and ITS2 are indicated by an arrows under the aligned sequences.

\section{Subfossil 96-G1 \\ Subfossil 96-G3 \\ Subfossil 96-G6 \\ Subfossil 94-G11}

Subfossil 96-G1

Subfossil 96-G3

Subfossil 96-G6

Subfossil 94-G11

Subfossil 96-G1

Subfossil 96-G3

Subfossil 96-G6

Subfossil 94-G11

Subfossil 96-G1
Subfossil 96-G3
Subfossil 96-G6
Subfossil 94-G11

Subfossil 96-G1

Subfossil 96-G3

Subfossil 96-G6

Subfossil 96-G11

Subfossil 96-G1

Subfossil 96-G3

Subfossil 96-G6

Subfossil 96-G11

Subfossil 96-G1

Subfossil 96-G3

Subfossil 96-G6

Subfossil 94.G11

Subfossil 96-G1

Subfossil 96-G3

Subfossil 96-G6

Subfossil 96-G11
GTGATTAAATCGAGAgTGTCTTCATTGACCTCTCACCCTTCACATCCACATACACCTGTGCACCGTTTGG

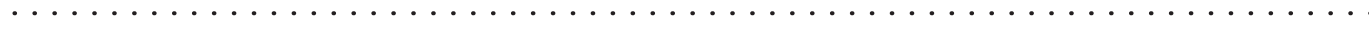

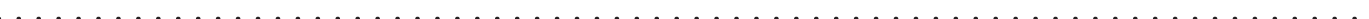

\section{$\rightarrow \operatorname{ITS} 1$}

СTCTTTTAAAAGACGCAAGTCTGCAAAGAGAGTCATCAATTTTATACATACCCCAGTCTTATGAATGTAA

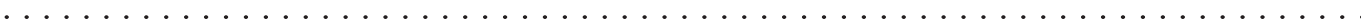

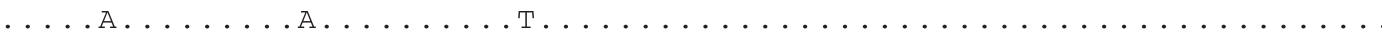

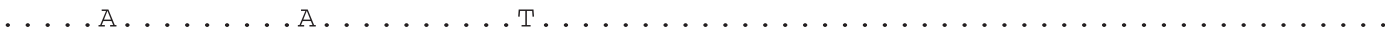

CAGTTTTAATAAACATAATAAAACTTTTAACAACGGATCTCTTGGTTCTCGCATCGATGAAGAACGCAGC

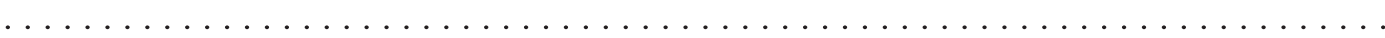

$$
\rightarrow 5.8 \mathrm{~S}
$$

GAAATGCGATAAGTAATGTGAATTGCAGAATTCAGTGAATCATCGAATCTTTGAACGCACCTTGCGCTCC

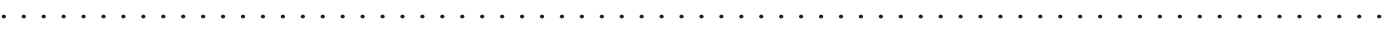

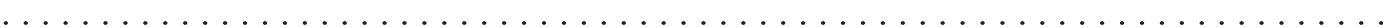

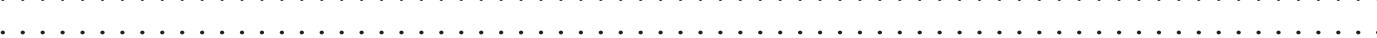

TTGGTATTCCGAGGAGCATGCCTGTTTGAGTGTCATGAAACTCTCAACCTTCAACTTTTTTTATTAAGGC

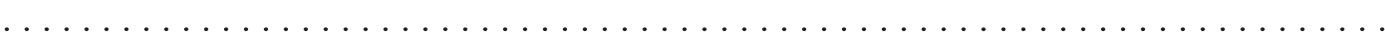

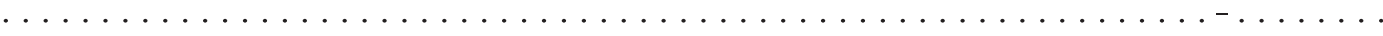

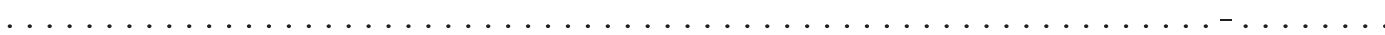
$\rightarrow$ ITS 2

TGAAGGCTTGGACTTGAGCGCTGCTGGTTTTCACTAACCGGCTCGCTTGAAATGAATTAGCAGATCCTTT

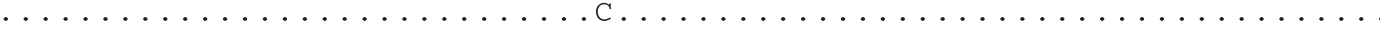

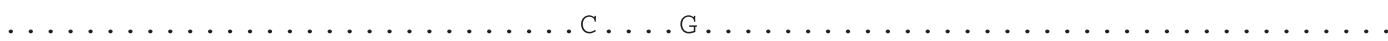
$\ldots \ldots \ldots \ldots \ldots \ldots \ldots \ldots \ldots \ldots \ldots \ldots \ldots \ldots \ldots \ldots \ldots \ldots \ldots \ldots \ldots$ TTGTAATCGGTTCCACTCGACGTGATAAGTATTTCGCCGAGGACATACGAAAGTATGGCCGAGATAA-GA

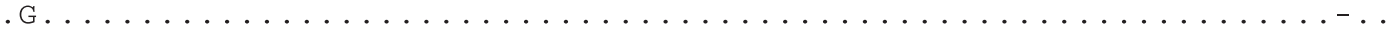

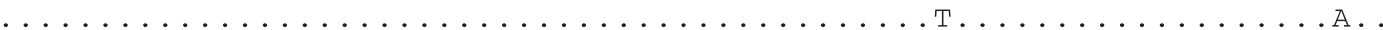

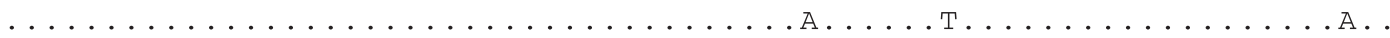

GAAGT-CTTTTAGATCCGCTTCTAATTCTTAGATCAAGCTTGCTTGACTAAACCCCATTTTATGA $\ldots \ldots-\ldots \ldots \ldots \ldots \ldots \ldots \ldots \ldots \ldots \ldots \ldots \ldots \ldots \ldots \ldots \ldots \ldots$

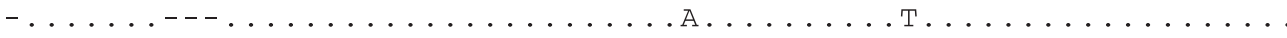
$-\ldots \ldots \ldots--\ldots \ldots \ldots \ldots \ldots \ldots \ldots \ldots \ldots \ldots \ldots \ldots$ for ca. 1350 years (Alstrup 1995), consistent with minor climatic cooling beginning in ca. $400 \mathrm{AD}$. Other samples were ice-covered for only 325 or 40 years (Table 1). Subfossil lichens were well-preserved and, except for minor changes in surface color and texture, morphologically indistinguishable from modern $U$. cylindrica, a circumpolar arctic-alpine species that is widely distributed along the coast of Greenland (Thomson 1984; Hansen and Andersen 1995). Levels of extracellular phenolic compounds are typically low in extant $U$. cylindrica and, though detectable using highly concentrated acetone extracts, were not observed with standard thin-layer chromatography in either subfossils or recent material. With the exception of a few forms of esterase, active enzymes detectable in modern $U$. cylindrica were not found in subfossils (Fahselt et al. 1995).

DNA isolated from small fragments of 25 lichen subfossils (Table 1) was apparently degraded during glacial preservation, as evidenced by the relatively small sizes (< approximately 800 nucleotides (nt)) of genomic DNA stained with ethidium bromide and visualized on agarose gels (not shown). Nevertheless, in all but 3 of the 25 collections, the extracted DNA was of sufficient quality for PCR amplifications of fungal nuclear ribosomal DNA (rDNA), providing fragments as long as 1700 nucleotides. Amplification products representing a 510-nucleotide conserved region of SSU rDNA were sequenced from 11 of the subfossil spec- 
Fig. 3. Maximum parsimony analysis of nuclear SSU rDNA sequences associated with two subfossil lichens (94-G11 and 94-G12) and 92 representative fungi (GenBank accession numbers are in parentheses), with subsequent placement of partial nuclear SSU rDNA sequences from nine subfossils lichens, nine modern umbilicate lichens, and fungi associated with clothing of the Tyrolean Iceman. A strict consensus of 54 equally parsimonious trees of 3933 is shown (consistency index $=0.354$ and retention index $=0.717$ for each). Bootstrap percentages from 200 replications are labeled on each supported branch. The major fungal groups, ascomycetes and basidiomycetes, supported in this analysis are labeled adjacent to their nodes. Placement of partial sequences are indicated by arrows at the base of strict consensus branches (not drawn to scale). Addition of partial SSU rDNA sequences from eight subfossils (G6, G9, G13, G14, G15, G16, G17, and G18) increased the number of trees to over 3000 and the tree length by 14 steps; from one subfossil (G7), 162 trees of one additional step; from a fungal clone associated with the Tyrolean Iceman (T44NS-2), 54 trees of 13 additional steps; and from nine modern umbilicate lichens (Umbilicaria species and Lasallia species), 54 trees of forty-three additional steps.

imens and aligned with corresponding sequences from nine extant representatives of umbilicate lichens, including $U$. cylindrica, two other ascomycetes, and two potential contaminants - a green algal lichen symbiont Trebouxia impressa and Homo sapiens (Fig. 1). In this region the SSU rDNA sequences from subfossil lichens had numerous nucleotide differences from those of modern $U$. cylindrica (approximately 6.5\%), many representing base pair compensatory changes across paired stems in the putative SSU rDNA secondary structure (not shown). Nor were the subfossil-associated sequences more similar to those of humans and algae, two potential contaminants. However, the subfossil-associated sequences from different samples and sites were highly similar, with $99 \%$ identity among ten SSU rDNA sequences and $>97 \%$ identity among four ITS sequences suggesting that most contained sequences from closely related fungi (Fig. 2).

When four partial SSU rDNA sequences from two representatives of $U$. cylindrica subfossil lichens and complete SSU rDNA sequences from two different genera of extant umbilicate lichens were used in a parsimony analysis with 90 other species of fungi, the analysis produced 54 equally parsimonious trees (EPTs) of 3933 steps that differed in the resolution within two clades of non-lichenized ascomycetous fungi, the Pezizales including Peziza badia to Plectania nigrella and the Taphrinomycotina including Protomyces inouyei to Neolecta irregularis, and one clade of basidiomycetous fungi, Agaricus bisporus, Pleurotus ostreatus, and Omphalina umbellifera (Fig. 3). The EPTs also differed in the relationships among the pairs of nearly identical subfossilassociated sequences and their close relatives; exclusion of the two sequences from one sample (94-G12) that were nearly identical to the sequences from another sample (94-G11) reduced the number of trees to six of 3930 steps. The 54 EPTs were compared using their likelihood scores, which ranged from 25604.19826 to 25625.60928 with ti/tv ratios of 1.72 to 1.73 . However, even the most extreme likelihood scores of the EPTs and trees generated by maximum likelihood were not significantly different according to the KishinoHasegawa test (respectively, $p \geq 0.1742,0.1783$ ).

Both the maximum likelihood and maximum parsimony trees agreed in placing the complete SSU rDNA sequences from extant umbilicate lichens among those of the ascomycetes, and the four partial SSU rDNA sequences from subfossil lichens among the basidiomycetes. However, the pairs of subfossil-associated sequences from different regions of the SSU rDNA were phylogenetically divergent. Two sequences (94-G11A and 94-G12A) amplified from the $5^{\prime}$ half of the SSU rDNA (nucleotides 54-872) were nearly identical to that of a fungus associated with the Tyrolean Iceman clothing (Rollo et al. 1995). The ascolichen-associated sequences differed from the latter sequence in only one or two nucleotide positions $(<1 \%)$ in the 278 nucleotide region of overlap. This group of three subfossil-associated sequences were sister taxa to Leucosporidium scottii in a clade including other yeast-like saprobes, Sporidiobolous johnsonii, Sporobolomyces roseus, and Rhodosporidium toruloides of order Sporidiales (Hawksworth et al. 1995; 588). All of the members of this clade shared a motif (5'-TCCCCTGGCAACACTTTGCCGAGA-3') between nucleotide positions 441 and 463, relative to Saccharomyces cerevisae, that may be unique to the Sporidiales (see also, Swann and Taylor 1995). Subsequent searches of databased sequences with Basic Local Alignment Search Tool (BLAST, Altschul et al. 1997) show greater than $98 \%$ similarity between these subfossil-associated sequences and the sequence of the mitosporic Bensingtonia yamatoana (GenBank accession No. D38239, AF101826) and the anamorphic Sporobolomyces inositophilus (GenBank accession No. AB021673) and Cryptococcus yarrowii (GenBank accession No. AB032658) (results not shown). Similarly, three sequences of PCR amplifications from 2000- or 4000-year-old ice core samples from northern Greenland (GenBank accession Nos. AF069821, AF069822, and AF069784) were reported by Willerslev et al. (1999) as phylogenetically related to Leucosporidium and the Sporidiales. This is not surprising as Leucosporidium is a psychrophilic basidioyeast found in or on polar snow and soils, as well as plants and lichens (Fell and Tallman 1984).

The remaining two sequences amplified from the 3 '-half of the SSU rDNA (94-G11B and 94-G12B, nucleotides 802 to 1750$)$ were closely related to other yeast-like saprobes Mrakia frigida and Mrakia psychrophilia within a clade including Udeniomyces species and Cystofilobasidium capitatum of the order Cystofilobasidiales (Fell et al. 1999). The subfossil-associated sequences differed in three to five nonambiguous nucleotides within the approximately 1080 nucleotide alignment from those of $M$. frigida, a psychrophilic basidioyeast found in polar snow and soil that was placed formerly in Leucosporidium (Fell and Tallman 1984). These partial SSU rDNA sequences were most similar (>98\%) to $M$. frigida and $M$. psychrophilia in BLAST searches of GenBank. Likewise, analysis of 600 nucleotides of large subunit (LSU) rDNA (data not shown) supported this relationship; DNA sequences associated with subfossil $U$. cylindrica were nearly identical (differing in only one nucleotide) to those of $M$. frigida (Fell et al. 1999). The partial SSU rDNA and partial LSU sequences flanked and overlapped the ITS region amplified from 94-G-11 and three 


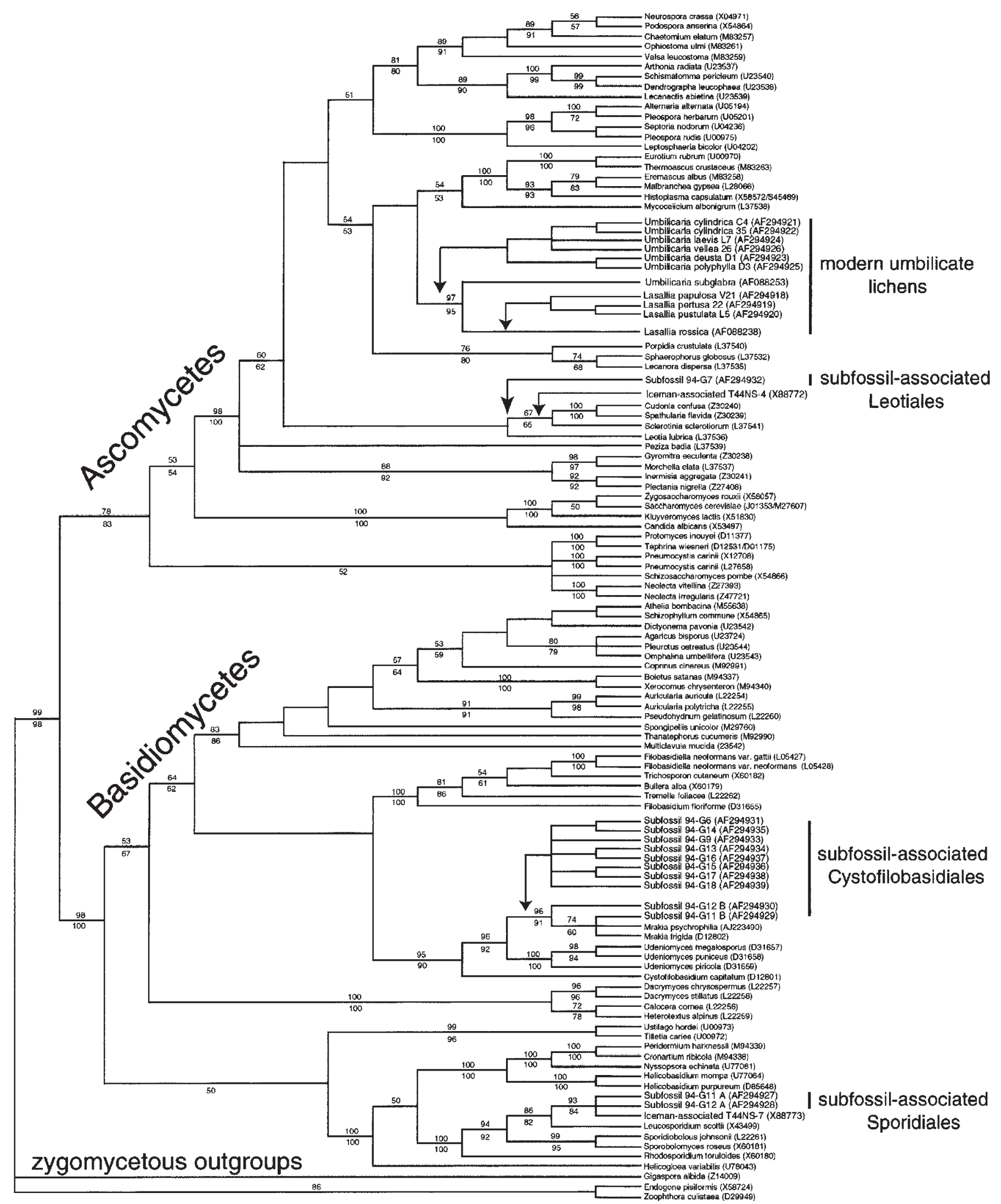

other subfossil-associated sequences by 200 and 50 nucleotides, respectively. The exact matching of these overlapping sequence regions suggests that the four ITS sequences also represent a fungus closely related to $M$. frigida, and not U. cylindrica (Ivanova et al. 1999). A 127-nt sequence (GenBank accession No. AF069900) PCR amplified from 
2000- or 4000-year-old ice core samples (Willerslev et. al 1999) differed in only three nucleotides from 94-G11 and G12. This demonstrated that Mrakia-related fungi are present in Greenland's glaciers and thus may well have been able to colonize lichens either covered by glacial ice or exposed by its melting.

Therefore, PCR amplification of the SSU from ascolichen specimens 94-G11 and 94-G12, collected at Qaanaaq in 1993, each produced sequences of at least two fungi that were not umbilicate ascolichens and probably represent other fungi colonizing the subfossil lichens. The preferential amplification of a fungus closely related to Leucosporidium scottii for the 5' SSU rDNA and of a fungus closely related to Mrakia frigida for the 3' SSU, ITS 1, 5.8S, ITS 2 and 5' LSU rDNA possibly reflects the abundance of DNA from the Mrakia-related fungi in the extractions as well as the relative specificity of the PCR amplification primers. For example, the primers used to amplify the $5^{\prime}$ SSU rDNA each have at least two mismatches relative to the Mrakia sequences; and the primers used to amplify the $3^{\prime}$ SSU rDNA have a critical mismatch (the $3^{\prime}$ nucleotide position) relative to the Leucosporidium sequence. The observation that such closely related fungi were associated with many specimens of subfossil ascolichens probably reflects the ubiquity of these yeast-like saprobes in Northern Greenland.

The inclusion in the analysis of partial SSU rDNA sequences from nine additional subfossils and nine additional modern umbilicate lichens produced parsimony trees topologically congruent with that shown in Fig. 3. Eight of the nearly identical partial sequences formed the sister lineage to the subfossil-associated sequences $94-G 11 B$ and 94-G12B, and $M$. frigida and Mrakia psychrophilla. The remaining subfossil-associated sequence, 94-G7, was basal to the clade representing the ascomycete order Leotiales, including Leotia lubrica, Sclerotinia sclerotiorum, and others, along with a second sequence T44NS-4 associated with the Tyrolean Iceman clothing (Rollo et al. 1995). The 94-G7 and T44NS-4 sequences, as well the sequence of a "viable" fungus (clone 'Sim C2') associated with the Tyrolean Iceman's clothing (Ubaldi et al. 1996), were nearly identical, differed in only 3 nucleotides in the 327-nucleotide region of overlap. Willerslev et al. (1999) also reported PCR-amplified sequences from ice core samples that are phylogenetically related to the Leotiales (GenBank accession Nos. AF069880, AF069882, and AF069884).

The ascomycete sequence 94-G7 associated with the subfossil lichens was in any case phylogenetically distant from the modern umbilicate lichens. The modern umbilicate lichens formed a monophyletic group within the Ascomycetes that was separate from the large lichen-forming order Lecanorales, represented by Porpidia crustulata, Sphaerophorus globosus, and Lecanora dispersa, in agreement with Stenroos and DePriest (1998). Thus, on the basis of phylogenetic analysis, the DNAs present in umbilicate lichens ice-preserved for over 1300 years were unambiguously foreign to modern umbilicate lichens.

Foreign sequences in fact were associated with most subfossils buried by ice for any period of time, even for only 40 years, but never with extant $U$. cylindrica from Greenland. Thus saprobic colonization, typically by basidiomycetous fungi, is enhanced even by brief glaciation. The ease with which $M$. frigida-like DNA was amplified suggested it was not damaged by ice burial and, thus, intimates that it was saprobically digesting the subfossil lichens during ice encasement and melting. (It is unlikely that colonization by Mrakia occurred during or after collection and storage in a desiccated state since the handling conditions were not favorable for growth of psychrophilic fungi.) Therefore, the presence of this foreign DNA probably represents ongoing colonization rather than a frozen vestige of an ancient community. Although basdioyeasts or other fungi could not be conclusively detected by microscopic examination of subfossils, small granules detected with electronmicroscopy inside hyphae suggested infection was intrahyphal.

Lichen thalli under subfreezing temperatures and high pressure beneath glaciers may undergo subtle changes in structure (Fahselt and Alstrup 1997b) and well-defined changes in chemistry. For example, levels of the major phenolic constituent, gyrophoric acid are reduced significantly in Umbilicaria specimens following ice burial (Fahselt and Alstrup 1997a). Since many phenolics have antifungal properties (Lawrey 1986), depletion of these compounds may permit colonization and saprobic digestion by microorganisms such as $M$. frigida. Reduced concentrations could be particularly critical in a species such as $U$. cylindrica where phenolics are inherently low. Intrathalline changes brought about by high pressures may also accelerate the degradation of DNA and leave little undamaged for molecular analyses even as the specimen retains a typical appearance. The association of the same or similar basidiomycetous and ascomycetous saprobes with ancient ascolichens, polar icecap cores, and grass clothing of the Tyrolean Iceman suggests that these fungi may be common contaminants of historical and prehistorical ice-preserved materials. Therefore, the molecular characterization of these saprobic fungi will be crucial to future studies of DNA and other constituents of subfossil and fossil tissues (Cano et al. 1993; DeSalle et al. 1992; Golenberg et al. 1990; Woodward et al. 1994). Although improved laboratory techniques may eventually reduce or eliminate contamination by modern DNAs of laboratory and human origin, it is only by understanding the ecology and genetic characteristics of modern microbes that we can document and authenticate ancient DNA.

\section{Acknowledgements}

We thank J. Fell for identification of Mrakia frigida from a partial nuclear LSU sequence, and N. Tuross and M.L. Braun for assistance and use of the "clean laboratories" of the Conservation Analytic Laboratory and the Laboratory of Molecular Systematics of the Smithsonian Institution. N.V.I. thanks S. Shetler and M. Sangrey for support and encouragement. The manuscript was improved by the helpful comments of D. Hibbett and an anonymous reviewer. This research was funded by grants from the Smithsonian Institution Arctic Studies Program, Scholarly Studies, National Museum of Natural History Research Initiative Programs, and a National Science Foundation - Partnerships for Enhancing Expertise in Taxonomy (DEB-9712484) award to P.T.D., a Postdoctoral Fellowship to A.G., and a National Museum of Natural History Research Training Program Fellowship to N.V.I. 


\section{References}

Alstrup, V. 1995. In situ cryo-subfossil vegetation in Northwest Greenland. Cryptogam. Bot. 5: 172-176.

Altschul, S.F., Madden, T.L., Schaffer, A.A., Zhang, J., Zhang, Z., Miller, W., and Lipman, D.J. 1997. Gapped BLAST and PSIBLAST: a new generation of protein database search programs. Nucleic Acids Res. 25: 3389-3402.

Cano, R.J., Poinar, H.N., Pieneazek, N.J., Acra, A., and Poinar, G.O., Jr. 1993. Amplification and sequencing of DNA from a 120-135million-year-old weevil. Nature (London), 363: 536-538.

Cooper, A. 1994. DNA from museum specimens. In Ancient DNA. Edited by B. Hermann and S. Hummel. Springer-Verlag, New York. pp. 149-165.

Culberson, C.F., and Ammann, K. 1970. Standardmethode zur Dunnschichtchromatographie von Flechtensubstanzen. Herzogia, 5: $1-24$.

DeSalle, R., Gatesy, J., Wheeler, W., and Grimaldi, D. 1992. DNA sequences from a fossil termite in Oligo-Miocene amber and their phylogenetic implications. Science (Washington, D.C.), 257: 1933-1936.

Fahselt, D., and Alstrup, V. 1997a. High performance liquid chromatography of phenolics in recent and subfossil lichens. Can. J. Bot. 75: 1148-1154.

Fahselt, D., and Alstrup, V. 1997b. Visualization of extracellular deposits in recent and subfossil Umbilicaria hyperborea. Lichenologist, 29: 547-557.

Fahselt, D., Alstrup, V., and Tavares, S. 1995. Enzyme polymorphism in Umbilicaria cylindrica in northwestern Greenland. Bryologist, 98: 116-122.

Fell, J.W., and Tallman, A.S. 1984. Genus 1. Leucosporidium Fell, Statzell, Hunter et Phaff. In The yeasts, a taxonomic study. 3rd Ed. Edited by N.J.W. Kreger-van Rij. Elsevier Science Publishers, New York. pp. 495-508.

Fell, J.W., Roeijmans, H., and Boekhout, T. 1999. Cystofilobasidiales, a new order of basidiomycetous yeasts. Int. J. Syst. Bacteriol. 49: 907-913.

Gargas, A., and DePriest, P.T. 1996. A nomenclature for fungal PCR primers with examples from intron-containing SSU rDNA. Mycologia, 88: 745-748.

Gargas, A., DePriest, P.T., Grube, M., and Tehler, A. 1995. Multiple origins of lichen symbioses in fungi suggested by SSU rDNA. Science (Washington, D.C.), 268: 1492-1495.

Golenberg, E.M., Giannasi, D.E., Clegg, M.T., Smiley, C.J., Durbin, M., Henderson, D., and Zurawski, G. 1990. Chloroplast DNA sequence from a miocene Magnolia species. Nature (London), 344: 656-658.

Handt, O., Richards, M., Trommsdorff, M., Kilger, C., Simanainen, J., Georgiev, O., Bauer, K., Stone, A., Hedges, R., Schaffner, W., Utermann, G., Bykes, B., and Pääbo, S. 1994. Molecular genetic analyses of the Tyrolean Ice Man. Science (Washington, D.C.), 264: 1775-1778.

Hansen, E.S., and Andersen, J. 1995. Greenland Lichens (Rhodos, Copenhagen).

Hasagawa, M., Kishino, H., and Yano, T. 1985. Dating of the human-ape splitting by a molecular clock of mitochondrial DNA. J. Mol. Evol. 36: 182-198.
Hawksworth, D.L., Kirk, P.M., Sutton, B.C., and Pegler, D.N. 1995. Ainsworth \& Bisby's dictionary of the fungi. 8th Ed. CAB International, Oxon, U.K.

Higuchi, R., Bowman, B., Freiberger, M., Ryder, O.A., and Wilson, A.C. 1984. DNA sequences from the quagga, an extinct member of the horse family. Nature (London), 312: 282-284.

Ivanova, N.V., DePriest, P.T., Bobrova, V.K., and Troitsky, A.V. 1999. Phylogenetic analysis of the lichen family Umbilicariaceae based on nuclear ITS1 and ITS2 rDNA sequences. Lichenologist, 31: 477-489.

Lawrey, J. 1986. Biological role of lichen substances. Bryologist, 89: $111-122$.

Nielsen, H., Engberg, J., and Thuesen, I. 1994. DNA from arctic human burials. In Ancient DNA. Edited by B. Hermann and S. Hummel. Springer-Verlag, New York. pp. 122-140.

Pääbo, S. 1985. Molecular cloning of ancient Egyptian mummy DNA. Nature (London), 314: 644-645.

Pääbo, S., Higuchi, R.G., and Wilson, A.C. 1989. Ancient DNA and the polymerase chain reaction. The emerging field of molecular archaeology. J. Biol. Chem. 264: 9709-9712.

Rogan, P.K., and Salvo, J.J. 1990. Study of nucleic acids isolated from ancient remains. Yearb. Phys. Anthropol. 33: 195-214.

Rollo, F., Sassaroli, S., and Ubaldi, M. 1995. Molecular phylogeny of the fungi of the Iceman's grass clothing. Curr. Genet. 28: 289-297.

Stenroos, S., and DePriest, P.T. 1998. SSU phylogeny of the cladoniiform lichens. Am. J. Bot. 85: 1548-1559.

Stuiver, M., and Reimer, P.J. 1993. Extended ${ }^{14} \mathrm{C}$ data base and revised CALIB $3.0{ }^{14} \mathrm{C}$ age calibration program. Radiocarbon, 35: 215-230.

Swann, E.C., and Taylor, J.W. 1995. Phylogenetic perspectives on basidiomycete systematics: evidence from the 18S rRNA gene. Can. J. Bot. 73 (Suppl. 1): S862-S868.

Swofford, D.L. 1999. PAUP*: Version 4. Sinauer Associates, Inc. Publishers, Sunderland, Mass.

Thomson, J.W. 1984. American arctic lichens, I. The macrolichens. Columbia University Press, New York.

Ubaldi, M., Sassaroli, S., and Rollo, F. 1996. Ribosomal DNA analysis of culturable deuteromyces from the Iceman's hay: comparison of living and mummified fungi. Ancient Biomol. 1: 35-42.

Vilgalys, T., and Hester, M. 1990. Rapid genetic identification and mapping of enzymatically amplified ribosomal DNA from several Cryptococcus species. J. Bacteriol. 172: 4238-4246.

White, T.J., Bruns, T.D., Lee, S.B., and Taylor, J.W. 1990. Amplification and direct sequencing of fungal ribosomal RNA genes for phylogenetics. In PCR protocols: A guide to methods and applications. Edited by M.A. Innis, D.H. Gelfand, J.J. Sninsky and T.J. White. Academic Press, New York. pp. 315-322.

Willerslev, E., Hansen, A.J., Christensen, B., Steffensen, J.P., and Arctander, P. 1999. Diversity of Holocene life forms in fossil glacier ice. Proc. Natl. Acad. Sci. U.S.A. 96: 8017-8021.

Woodward, S.R., Weyand, N.J., and Bunnell, M. 1994. DNA sequence from Cretaceous period bone fragments. Science (Washington, D.C.), 266: 1229-1232. 